REMARKS.

In the example now recorded, as is frequent in such instances, there was associated a considerable degree of gastric disturbance, which required primary attention. The milk diet proved peculiarly suitable, and although the specific gravity of the urine continued the same under its use, in all other respects he improved. There was, however, no decided reduction in the specific gravity of the urine, or change in the essential character of the disease, until the patient totally abstained from bread, under which plan in December, 1840, every symptom of disease had disappeared. The specific gravity of the urine rose after eating an apple, but again subsided under prudent restrictions. Subsequently, however, his firmness yielded, and after various fluctuations corresponding with the degrees of his indulgence, he ultimately fell a victim to the disease.

I believe that in cases of true diabetes mellitus, if the use of bread is allowed the final issue will generally correspond. Exceptions to this rule are indeed on record. For example, a case occurred some time since at Guy's Hospital, which appeared to recover under the use of nauseating doses of ipecacuanha wine.

Mr. Heineken (London Med. Repos., Feb., 1823) has related an instance which yielded in three months to the use of 600 grains of opium; and the sulphur bath appears to have been singularly efficacious in the treatment of the patient Gosling, whose case is described by Dr. L. Bardsley (Hospital Facts and $\mathrm{Ob}$. servations), the quantity of urine being in fifteen weeks reduced from twenty-six to two pints, and the specific gravity from $1 \cdot 038$ to $1 \cdot 010$. Lately the iodide of iron, in doses of five grains thrice a-day, is said to have proved efficacious, yet it must be acknowledged as a general rule, deducible from the recorded instances of the disease, that durable improvement occurs only under the discontinuance of bread and of all vegetables abounding in starch. Our great aim in treatment should be to restore the function of the skin, the relation of which to the kidneys is of obvious importance, and to withhold all articles of diet easily convertible into sugar. The employment of other measures may be regulated by collateral circumtances, but improvement in the essential symptoms will almost uniformly be promoted or retarded, according to the degree of indulgence or restriction in the use of bread.

When we consider the remarkable power of habit in enabling man to adapt himself to every variety of regimen, and recal such instances as that of the miners of Chili fulfilling their unparalleled labors on a diet of beans and bread; or of some North American tribes living solely on fish; or, more especially, the Guachos of the Pampas, passing their life on horseback, subsisting for many months exclusively on beef, - we are surprised that, under a disease such as we have described, the conviction of its necessity should be inadequate to enforce resolution; and the inquiry is naturally suggested whether a complete change of the whole plan of life might assist us in conquering the difficulty, and whether an active, open air life, resembling that of the Guachos, might contribute to render a fat meat diet, like that of those dexterous horsemen, an agreeable support of life.
CASE OF WATER CA NKER, WITH REMARKS.

TO THE EDITORS OF THE PROVINCIAL MEDiCAL JOURNAL.

Gentlemen,-I shall feel much obliged by your inserting the following case in the Provincial Medical Journal.

I am, Gentlemen, Your obedient servant,

Yeovil, July 18, 1843 W. Tomkins, M.D.

I beg, through the medium of the Provincial Medical Journal, to call the attention of my professional brethren to an important disease, which, however, I believe is but little known in this country, as far as I have been able to ascertain from extensive inquiry, both amongst my professional friends and the various authors to which I have referred. I remember many years since to have read an account of the affection I am about to describe, either in a work on military surgery or in some periodical; but as it was long before my attention had been practically drawn to the disease, I omitted to make any note of the circumstance, and have, consequently, been unable to refer to it. The only corroborative testimony I can give, to confirm the nature of the affection I am about to relate, is a statement made to me by an army surgeon, now deceased, who accompanied the unfortunate Walcheren expedition, and who, during my attendance on him, on account of diseased liver and enormous enlargement of the spleen-the sequelæ of intermittent fever contracted during that disastrous enterprise, said that he had seen numerous instances of "water canker," a disease well known in Holland, and described it as being the result of exposure to marsh miasmata, and attended with great prostration.

I have seen three cases; but, as all of them presented similar symptoms and appearances, shall describe-one only, which was the most severe, and occurred in the same individual three succeeding years during the month of January, and on each occasion appeared to have been induced by one and the same cause.

Case. - I was desired to visit Mr. James Osborne, of llchester, Somerset, whose father was a respectable farmer, and found my patient had been exposed for several hours to the damp of the meadows bordering on the river for many successive nights, attending his flock in the lambing season. On visiting him, I at once said he was salivated, but he most solemnly assured me he had neither taken or applied externally medicine of any kind; the fœtor of the breath, however so exactly resembled that produced by mercury, that I thought I could not have been deceived. I now examined the mouth attentively, and found the tongue swollen, and deeply indented from its pressure against the teeth; the gums and the whole of the mucous membrane of the mouth covered with a white incrustation, similar to what we observe in apthæ, except that it was much thicker. I used a syringe, and, having cleansed this away, found the mucous membrane highly inflamed, with the glands and follicles extremely vascular; in a few minutes, however, the mouth was filled with an acrid, watery fluid; the lips were very much swollen; the countenance anxious; the pulse slow, soft, and full; the bowels constipated; and the patient complained of great sinking at the 
scrobiculus cordis, unaccompanied by pain on pressure, but there was great pain in the ears and muscles of the neck. The system altogether appeared relaxed, with a clammy moisture on the skin; the urine high colored and scanty. I directed an encma to open the bowels, but this having failed in its intended effect, three drops of croton oil were given, with a few grains of aromatic confection and powdered gum arabic, and made into a small draught, with half an ounce of rose water, which operated freely; I also prescribed two grains of the sulphate of quinine to be taken every four hours. On the following day I found my patient much the same, except that the symptoms of depression were more urgent, and the discharge from the mouth enormous, amounting to several pints in the twenty-four hours; the discharge manifested an acid character. I now desired that port wine should be taken freely in addition to the quinine, but requested the patient and attendants to discontinue it if delirium ensued, or the head appeared much affected. The following morning I found the patient was much in the same state, except that the incrustation on the mouth appeared thicker. He had taken two bottles of port wine during the twenty-four hours without any effect on the pulse or head, and his mother informed me that they were obliged to give him some at least every ten minutes, as he complained so much of the dreadful sinking, and, if he omitted it longer, he found great difficulty in swallowing. I desired that the quinine and wine might be continued, and, in addition, an electuary with the sesquicarbonate of ammonia and gum camphor mixed with honey, to be taken alternately every two hours with the quinine, and a draught, with two drops of croton oil, to act on the bowels. The next day I found him slightly improved, but was surprised to hear that he had taken six bottles of port wine, in addition to his medicine, without affecting his head or quickening his pulse, and, as he appeared improving, this quantity was continued for six or seven days longer with the best effect; but, at the expiration of that time, his symptoms were so muchimproved that the quantity was daily diminished, and in its stead, as the power of swallowing improved, he took the decoction of bark with quinine, and alterative doses of blue pill, with the compound rhubarb pill, at night, under which plan he gradually regained his strength.

On the two years following the first occurrence of this disease, Mr. Osborne had returns of the affection, but each rather less severe than the first, in succession. I have since this seen two other cases in different individuals, but, as the symptoms and the treatment pursued were pretty similar, I need not detail them.

In each instance of these diseases the subjects of them had been exposed to the influence of the miasmata during the night, and I think it, therefore, fair to infer that dew damp was the exciting cause, the baneful influence of which on the human constitution is well known to professional men. The quantity of wine which was taken appears enormous, and, had I not been an eye-witness to the fact, I should have scarcely believed that so much stimulus could have been introduced into the system with impunity; it tends, however to show the highly debilitating nature of the disease, and its prostrating effect on the nerrous system, which must have sunk under it had this been omitted.

I am convinced that the affection was a local one, for although I expected it would extend over the whole mucous surface of the intestinal canal, there were no subsequent symptoms to prove that such was the case.

\section{CASE OF POPLITEAL ANEURYSM}

CURED BY

PRESSURE ON THE FEMORAL ARTERY.

The following case is related by $\mathrm{Mr}$. Bellingham in the " Dublin Journal :"-

James Hayden, a servant, aged thirty-two, labors under popliteal aneurysm on the right side.

The tumor is seated high in the popliteal space; it occupies the entire ham, and projects also backwards it measures three inches in diameter transversely, and a little more from above downwards. On laying the hand upon it a very strong impulse is felt, both posteriorly and laterally. On placing the stethoscope on it a bruit de souffet, resembling a short but strong whiff, is heard. On making pressure on the femoral artery, all pulsation in the tumor ceases, and on continuing the pressure, it diminishes, and can be completly emptied.

The patient states that his attention was attracted to it about three months ago, in consequence of his feeling a weakness in the limb on coming down stairs; the following day he perceived a tumor in the ham, but he did not observe any pulsation in it at that time ; a week afterwards when in bed, he felt a pulsation which has continued since. Subsequently he has suffered from some degree of stiffness and weakness of the knee, which he attributed to rheumatism. Within the last four or five days the ankle has become swollen, the veins of the leg are also slightly varicose. He complains of a feeling of numbness down the back of the leg to the ankle, and he says he suffers some pain when he extends the limb in bed. The disease, however, has not much interfered with the motions of the limb; indeed he fancied he was better after exercise, and he had walked to the hospital.

He has no recollection of ever straining the limb, or receiving any injury in the part; he is an indoor servant, and has never been employed about horses. His general health is very good, the circulation is tranquil, and the heart's action natural and regular; he never was in the habit of drinking, never took mercury. He cannot refer the disease to any cause, and had applied at the hospital on the day of his admission merely to get something to rub to the limb, under the impression that he labored under rheumatism of the part.

In consultation upon the case with Mr. Cusack and Mr. Hutton, it was determined to gire a trial to pressure upon the artery above the tumor, and $\mathrm{Mr}$. Cusack, having kindly placed at my disposal Sir Philip Crampton's apparatus, which had been successfully employed by him in a recent case at Stevens' Hospital, one similar to it was constructed by Mr. Millikin.

April 3. The instrument was applied this day; the pad was placed upon the artery as it passes over the 